\title{
Simultaneous pancreas and kidney transplantation for end-stage kidney disease patients with type 2 diabetes mellitus: a systematic review and meta-analysis
}

\author{
Yu Cao ${ }^{1} \cdot$ Xiaoli Liu ${ }^{2} \cdot$ Xiangyu $\operatorname{Lan}^{1} \cdot$ Kaiwen $\mathrm{Ni}^{2} \cdot$ Lin $\mathrm{Li}^{1} \cdot$ Yingxin $\mathrm{Fu}^{1}$ (I)
}

Received: 15 April 2021 / Accepted: 13 June 2021 / Published online: 19 July 2021

(c) The Author(s) 2021

\begin{abstract} advantage compared with KTA.

PROSPERO registration number outcomes · Meta-analysis

$\begin{array}{ll}\text { Abbreviations } \\ \text { SPK } & \text { Simultaneous pancreas-kidney transplantation } \\ \text { ESKD } & \text { End-stage kidney disease } \\ \text { DM } & \text { Diabetes mellitus } \\ \text { T2DM } & \text { Type } 2 \text { diabetes mellitus } \\ \text { T1DM } & \text { Type } 1 \text { diabetes mellitus } \\ \text { KTA } & \text { Kidney transplantation alone } \\ \text { CI } & \text { Confidence interval } \\ \text { CNKI } & \text { China National Knowledge Infrastructure }\end{array}$
\end{abstract}

Purpose The indications for patients with type 2 diabetes mellitus (T2DM) combined with end-stage kidney disease (ESKD) undertaking simultaneous pancreas and kidney transplantation (SPK) remain an unresolved issue. This study aimed to systematically review the survival outcomes of SPK among T2DM-ESKD patients.

Methods Online databases including PubMed, MEDLINE, EMBASE, and the CENTRAL Library, CNKI, Chinese Biomedical Literature Database, and Wan-Fang database were used to locate the studies of ESKD patients with T2DM undertaking SPK up to May 2021. A third reviewer was consulted if there were disagreements. Data were analyzed with STATA (15.0). Results Nine cohort studies were identified. The pooled 1-year, 3-year, and 5-year patient survival rates of patients with T2DM and ESKD after SPK were 98\%, 95\%, and 91\% respectively. Comparing the treatment effect of SPK between type 1 diabetes mellitus (T1DM) and T2DM, the survival estimates were comparable. For T2DM patients, SPK had a survival

Conclusions The synthesized clinical outcomes of T2DM patients with ESKD after SPK were relatively better than KTA, but a subset of T2DM-ESKD patients who would benefit the most from SPK was to be defined.

CRD42019118321. Date of registration: 14 Jan 2019 (retrospectively registered)

Keywords Simultaneous pancreas and kidney transplantation $\cdot$ Kidney transplantation alone $\cdot$ Type II diabetes $\cdot$ Survival

Yingxin $\mathrm{Fu}$

yingxinfu@nankai.edu.cn

1 Department of Kidney and Pancreas Transplantation, Tianjin First Central Hospital, Tianjin, China

2 Research Center of Clinical Epidemiology, Peking University Third Hospital, Beijing, China

\section{Introduction}

It was estimated that there were more than 463 million people were living with diabetes mellitus (DM) worldwide, and more than $90 \%$ of them were diagnosed with type 2 diabetes (T2DM) [1, 2]. In Europe, the number of DM is estimated to be 58 million [2]. Over the past years, China has witnessed a surging prevalence of diabetes, with the largest number of diabetic patients in the world [3] and ranked number one in the 2019 International Diabetes Federation Diabetes Atlas Report [2]. Furthermore, diabetes is the leading cause of end-stage kidney disease worldwide; in conjunction with hypertension, it resulted in at least $80 \%$ end-stage kidney disease (ESKD) [4]. In the USA, Japan, New Zealand, and Singapore, about $50 \%$ of ESKD are primarily due to DM [4].

Since the first pancreas transplantation was done at Minnesota University in 1966, with the improvement of surgical techniques and introduction of immunosuppressive agents of cyclosporine, the number of pancreas transplantation 
has increased steadily, especially for simultaneous pancreas transplantation $[5,6]$. SPK has been a medically effective and cost-effective method for T1DM, but there was no consensus on SPK for the T2DM population, especially in the aspect of selection criteria [6, 7]. In the 2020 Kidney Disease: Improving Global Outcomes (KDIGO) guideline, patients with ESKD and T1DM were recommended for SPK, while there were no suggestions for those with T2DM [8]. Data on SPK outcomes in T2DM patients began appearing in the annual International Pancreas Transplant Registry (IPTR) reports since the mid1990 s $[9,10]$. The number has gradually increased with treatment outcomes equivalent to or better than other treatment alternatives on T2DM nephrological patients [11]. The cases of SPK were steadily increasing in Europe as well [12]. Considering the growing size of T2DM-ESKD recipients receiving SPK and the need to synthesize existing knowledge to inform clinical practice, we sought to review systematically and summarize available survival data in these patients. We planned to (i) synthesize the risk of death after SPK for T2DM-ESKD patients; (ii) assess the quality of available epidemiological data; (iii) summarize the hazard risk of mortality between SPK T2DM recipients and their counterparts; and (iv) estimate the relative risk of commonly reported complications between SPK T2DM recipients and their counterparts.

\section{Methods}

This meta-analysis was written in accordance with Preferred Reporting Items for Systematic Reviews and Meta-Analyses [13].

\section{Eligibility criteria}

This review included cohort studies estimating the survival outcome of SPK for T2DM patients combined with ESKD since no trials were available. All studies that reported SPK survival outcomes of T2DM-ESKD patients in English or Chinese were included. There were no restrictions on the type of setting. The year of publication was limited for Chinese studies. Those conducted before 2010 were excluded during the study selection process, considering the implementation of the Donation after Citizen's Death in 2010 [14]. Primary outcomes were patients' and grafts' survival rates. Secondary outcomes were hazard ratio between T1DM and T2DM, SPK, and KTA, and risk ratio of complications was recorded as well.

\section{Information sources, search strategy, and records management}

Only quantitative studies were searched. PubMed, MEDLINE (1946 onwards), EMBASE (1947 onwards), the CENTRAL trials registry of the Cochrane Collaboration (1948 onwards), China National Knowledge Infrastructure (CNKI, 1994 onwards), Chinese Biomedical Literature Database (CMB, 1978 onwards), and Wan-Fang database (1998 onwards) were searched to May 2021. The specific search strategies were created by two team members in consultation with an expert in medical informatics. Search strategies were included in Supplemental digital contents Table 1 (SDC-Table S1). As relevant studies were identified, the reviewers checked for additional relevant articles. Records identified through the database were managed with NoteExpress, which is an information manager for researchers and designed to help organize research notes and bibliographic references and generate bibliographies automatically (http:// www.inoteexpress.com/aegean/).

\section{Study selection}

The titles and abstracts of all of the references generated by search strategies were screened independently by two review members to identify eligible studies. Disagreements were resolved by discussion and consensus between the two reviewers. If disagreement persisted, the final decision was made by consensus with the involvement of the third member of the team. The full-text articles of included abstracts and uncertain abstracts were retrieved and reviewed by two members for inclusion separately. Reasons for study exclusion were recorded.

\section{Data collection process}

Two authors independently extracted and record data based on a standardized data extraction form (EXCEL form) designed by YXF and YC. The following items were extracted from the identified articles, name of the first author, publication year, title, study purpose, country, city/ region, data source, study design, definition of T2DM, operation technique, number of cases, study period, age, BMI, sex, duration of DM, pre-operation comorbidities, induction agents, immunosuppressive agents, follow-up period, definitions and rates of complications, definition of graft failure, survival rate, and HR. Adjusted data were preferentially selected if available [20]. When the eligible studies failed to provide specific survival data and HR with $95 \% \mathrm{CI}$, the data in figures were extracted using Engauge Digitizer (version $10.11 \mathrm{http}: / /$ markummitchell.github.io/engauge-digitizer/), a free publicly available software, and the HR with $95 \% \mathrm{CI}$ was calculated using methods suggested by Tierney et al. [21].

\section{Risk of bias in individual studies}

The Newcastle-Ottawa Scales (NOS) recommended by the Cochrane handbook were adopted for quality assessment [22, 23]. Giving that enrolled studies were 


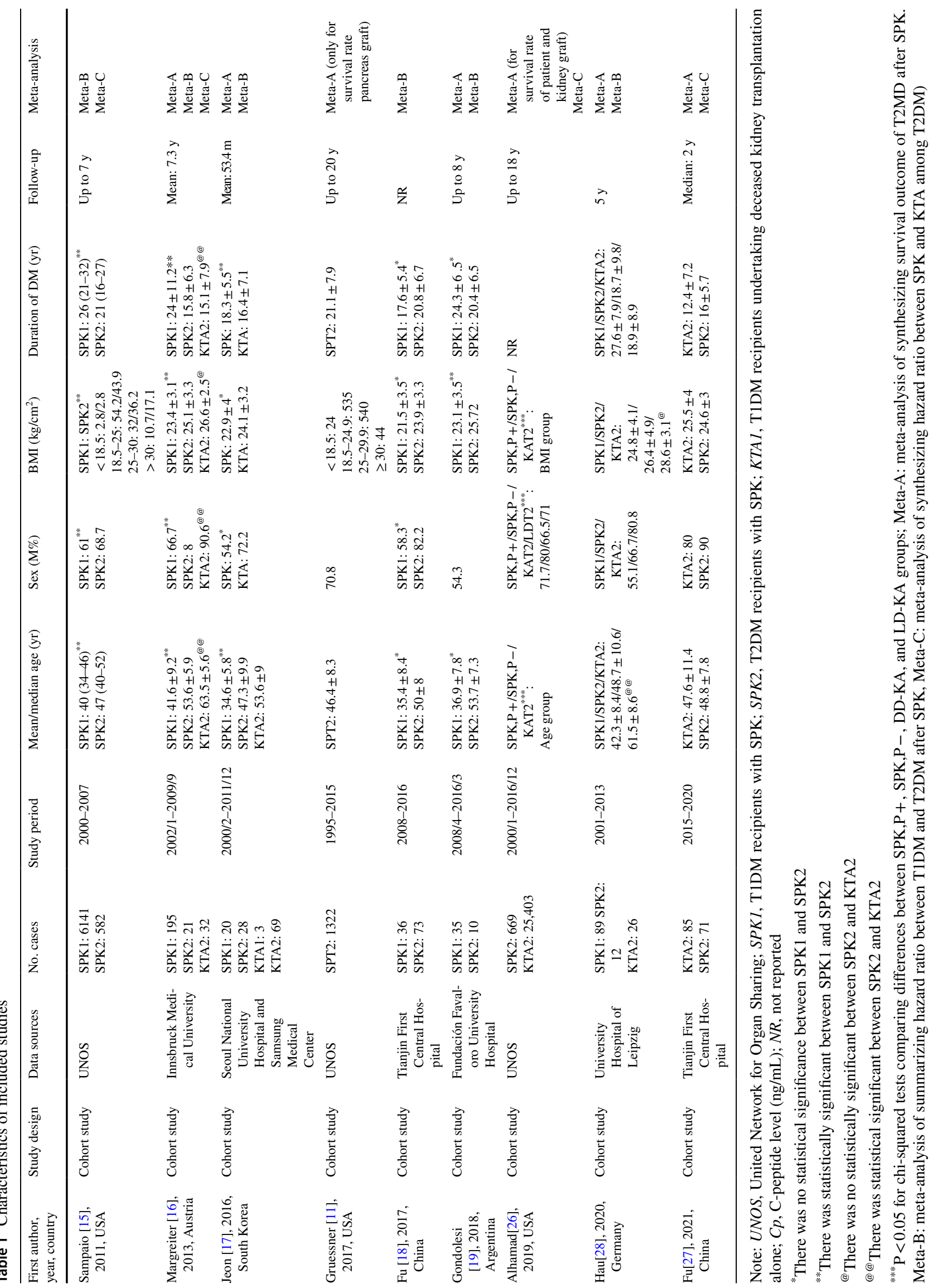


retrospective cohort design with various sources of heterogeneity, modification on NOS was undertaken. The final customized NOS was presented in SDC-Table S2. Two reviewers independently appraised the study quality. Disagreements between the reviewers over the risk of bias were resolved by discussions with a third reviewer (YXF).

\section{Data synthesis}

Survival rates and HRs were combined with the random effect model. All statistical syntheses and analyses were performed using STATA (15.0). Statistical heterogeneity was assessed using the $\mathrm{I}^{2}$ statistic $(<0 \%$ : very slight heterogeneity; $30 \%$ to $60 \%$ : may represent moderate heterogeneity; $50 \%$ to $90 \%$ : may represent substantial heterogeneity; $75 \%$ to $100 \%$ : considerable heterogeneity) [24]. If the heterogeneity was above $50 \%$, sensitivity analysis would be conducted. Evidence surrounding definitions of DM, baseline characteristics of recipients, definitions of graft failure, and complications which might play a role in survival outcomes was synthesized qualitatively. Funnel plots were not used to visualize the publication bias in each group since the number of included studies in the meta-analysis was less than $10[22,25]$.

\section{Results}

\section{Search results}

The search yielded abstracts for 1677 publications. After excluding duplicate articles and screening the abstracts, 1394 were remained for further review. Then, 153 copies of the full published version of each study were obtained, after excluding records which did not refer to SPK among recipients with T2DM in the title or abstract. Sixty-nine full texts were excluded next due to lack of survival outcomes of patients or grafts, leaving 16 eligible publications. Next, among the 16 studies, 9 were involved in the difference data synthesis process $[11,15-19,26-28]$. Considering the study quality and data completeness on primary outcomes, 6 were included for synthesizing survival outcomes of T2MD patients after SPK [11, 15-17, 19, 26-28], 6 studies were included for summarizing the hazard ratio between T1DM and T2DM after SPK [15-19, 28], 3 studies were included for synthesizing hazard ratio between the SPK group and the KTA group [16, 26, 28], and each meta-analysis had no overlapping samples. (Fig. 1, Table 1). The details of excluded studies with overlapping samples were in the SDC-Table S3.

\section{Study characteristics}

Characteristics of the included studies were presented in Table 1 and Table 2 (additional information in SDC-Table S4). All included studies were retrospective cohort studies. In accordance with the eligible criteria, all reports included a cohort of T2DM ESKD patients undertaking SPK. Considering the geographical coverage of the study, included studies were from the USA, Argentina, Germany, Austria, South Korea, and China.

\section{Definition of T2DM and definition of renal failure and pancreas failure}

As shown in Table 2, a variety of DM definitions has been witnessed among the included studies. Studies adopted center-specific criteria in selecting DM candidates for SPK [16, 17, 26-28], which classified DM around the C-peptide level, BMI of $30 \mathrm{~kg} / \mathrm{m}^{2}$, age, and pancreatic antibodies [15-17, 19, 29-31]. UNOS's definition of T2DM was based on the SPK transplant recipient registration form and the diagnosis of end-stage pancreas disease (ESPD) [15].

A consensus on the definition of renal failure among enrolled studies was witnessed, which was kidney retransplantation, returning to dialysis, or patient death. However, the definitions of pancreas graft failure varied. Most studies defined pancreas graft failure as insulin resumption, patient death, or pancreas graft removal.

\section{Methodological quality of included studies}

Methodological quality scores ranged from 4 to 8 on a modified scale of 0 to 11 (Table 3). A majority of studies showed good quality in patient selection and outcome assessment $[11,15-19,26,28]$. The main heterogeneity between studies might arise from the sample size disparity, poor comparability of cohorts on the basis of study design or analysis, and insufficient reporting of follow-ups. Specifically, most studies [16-19, 27, 28] had a sample size of T2DM undertaking SPK below 100 and the number in UNOS studies $[11,15,26]$ was more than 500; only 3 studies $[15,26,27]$ reported 
adjusted hazard ratio on T1DM vs. T2DM or SPK vs. KTA; the majority of studies neither reported median or mean follow-up period, nor described the details of the follow-up-losses (Table 1 and 3) [11, 1519, 2628].

\section{Survival rates}

Pooled 1-year, 3-year, and 5-year survival rates of patients, kidney graft, and pancreas graft (Fig. 2A-C)

Six studies $[11,16,17,19,26-28]$ were included for meta-analysis of survival rates of SPK among T2DM recipients (Fig. 2A-C). The pooled 1-year, 3-year, and 5 -year patient survival rates of T2DM combined with ESKD patients after SPK were 98\% (95\% confidence interval (CI), 96\%-100\%, $\left.\mathrm{I}^{2}=0 \%, \mathrm{p}=0.646\right), 95 \%$ $\left(95 \% \mathrm{CI}, 91 \%-99 \%, \mathrm{I}^{2}=39.6 \%, \mathrm{p}=0.142\right)$, and $91 \%$ (95\%CI, 87\%-96\%, $\mathrm{I}^{2}=0 \%, \mathrm{p}=0.438$ ) (Fig. 2A). For kidney graft survival outcome, the synthesized 1-year, 3 -year, and 5-year survival rates were 97\% (95\% CI, $\left.94 \%-99 \%, \mathrm{I}^{2}=0 \%, \mathrm{p}=0.611\right), 94 \%$ (95\% CI, 91\%-97\%, $\left.\mathrm{I}^{2}=0 \%, \mathrm{p}=0.556\right)$, and $89 \%\left(95 \% \mathrm{CI}, 85 \%-93 \%, \mathrm{I}^{2}=0 \%\right.$, $\mathrm{p}=0.579$ ) (Fig. 2B). The heterogeneities among studies were slight.

The pooled 1-year, 3-year, and 5-year pancreas survival rates were $91 \%$ (95\% CI, $86 \%-95 \%, \mathrm{I}^{2}=47.1 \%$, $\mathrm{p}=0.092), 86 \%\left(95 \% \mathrm{CI}, 78 \%-94 \%, \mathrm{I}^{2}=75 \%, \mathrm{p}=0.001\right)$, and $81 \%$ (95\%CI, 78\%-84\%, $\mathrm{I}^{2}=0 \%, \mathrm{p}=0.964$ ) (Fig. 2C). Since there was substantial heterogeneity in the 3 -year survival rate analysis, sensitivity analyses were conducted and the result indicated that Fu et al.' s study [27] was the reason of heterogeneity which might be due to the short median follow-up period (SDC-Figure S1).

\section{Meta-analysis of patient and graft HR among T2DM compared with T1DM (Fig. 3A-C)}

Six studies compared the survival rates between T1DM and T2DM [15-19, 28] (Fig. 3A-C). The pooled results indicated that T2DM has comparable survival estimates of patient death and graft failure with T1DM (for patient death, meta-hazard ratio (HR): 1.16, 95\% CI, 0.92-1.47, $\mathrm{I}^{2}=0 \%, \mathrm{p}=0.487$; for kidney graft failure, meta-HR: 1.18 , $95 \% \mathrm{CI}, 0.98-1.41, \mathrm{I}^{2}=0 \%, \mathrm{p}=0.657$; for pancreas graft failure, meta-HR: $1.10,95 \% \mathrm{CI}, 0.94-1.30, \mathrm{I}^{2}=0 \%, \mathrm{p}=0.632$ ) (Fig. 3A-C).

\section{Meta-analysis of patient and graft HR among T2DM after SPK compared with KTA (Fig. 4A-B)}

Four studies were included for meta-analysis of survival outcome comparison between SPK and KTA among T2DM patients [16, 26-28] (Fig. 4A-B). The result indicated an increased survival risk after KTA among T2DM patients (pooled HR: 2.33, 95\% CI, 1.64-3.32; $\mathrm{I}^{2}=0 \%, \mathrm{p}=0.746$ ) (Fig. 4A). In addition, renal survival outcome was superior in the SPK group as well (pooled HR, 2.06; 95\% CI, $1.53-2.76 ; \mathrm{I}^{2}=0 \%, \mathrm{p}=0.956$ ) (Fig. 4B).

\section{Meta-analysis of complications RR among T2DM compared with T1DM (SDC-Figure S2)}

The rates of rejection, infection, DGF of kidney graft and DGF of pancreas graft, and other types of complications were recorded and analyzed from included studies (Table 4). Four studies [15, 16, 18, 28] reported DGF data, 4 studies reported infection rates $[15,16,18$, $28]$, and 5 studies reported rejection data $[15-18,28]$ (Table 4 and SDC-Figure S2A-D). The risk of kidney graft DGF was significantly higher in the T2DM group (meta-RR: $1.47,95 \% \mathrm{CI}, 1.17-1.85, \mathrm{I}^{2}=0 \%, \mathrm{p}=0.935$ ) compared with the T1DM group, while the risks of rejection, infection, pancreas graft, and DGF were comparable between the T2DM group and the T1DM group (SDC-Figure S2B-D). Since the heterogeneity of the analysis of rejection rates was above $50 \%$, Hau et al.'s study [28] which reported the cumulative combined kidney and pancreas rejection rate might be the cause of diversity. A sensitivity analysis excluding Hau et al.'s study [28] was conducted; the result was presented in SDC-Figure S3.

\section{Meta-analysis of complications RR among SPK compared with KTA among T2DM patients (SDC-Figure S4)}

Three studies reported cases of rejection, DGF of kidney graft, and infection in the SPK group and the KTA group among T2DM patients [16, 27, 28] (Table 4). The results indicated that the risks of kidney graft DGF and infection was not significantly higher in the KTA group (meta-RR of kidney graft DGF: $3.07,95 \% \mathrm{CI}, 1.37-6.89, \mathrm{I}^{2}=0 \%$, $\mathrm{p}=0.599$; meta-RR of infection: $0.81,95 \% \mathrm{CI}, 0.33-2.01$, $\left.\mathrm{I}^{2}=65.2 \%, \mathrm{p}=0.056\right)($ SDC-Figure $\mathrm{S} 4)$. A sensitivity analysis excluding Fu et al.'s [27] study was conducted. (SDCFigure S4). The risk of developing rejection in the SPK group was not significantly higher (meta-RR: $0.55,95 \% \mathrm{CI}$, $0.21-1.45, \mathrm{I}^{2}=38 \%, \mathrm{p}=0.199$ ).

\section{Discussion}

Previously, Chan et al. has attempted to address the question about the controversy of conducting SPK on T2DM patients in a review which vaguely concluded that the 
Fig. 1 PRISMA flowchart

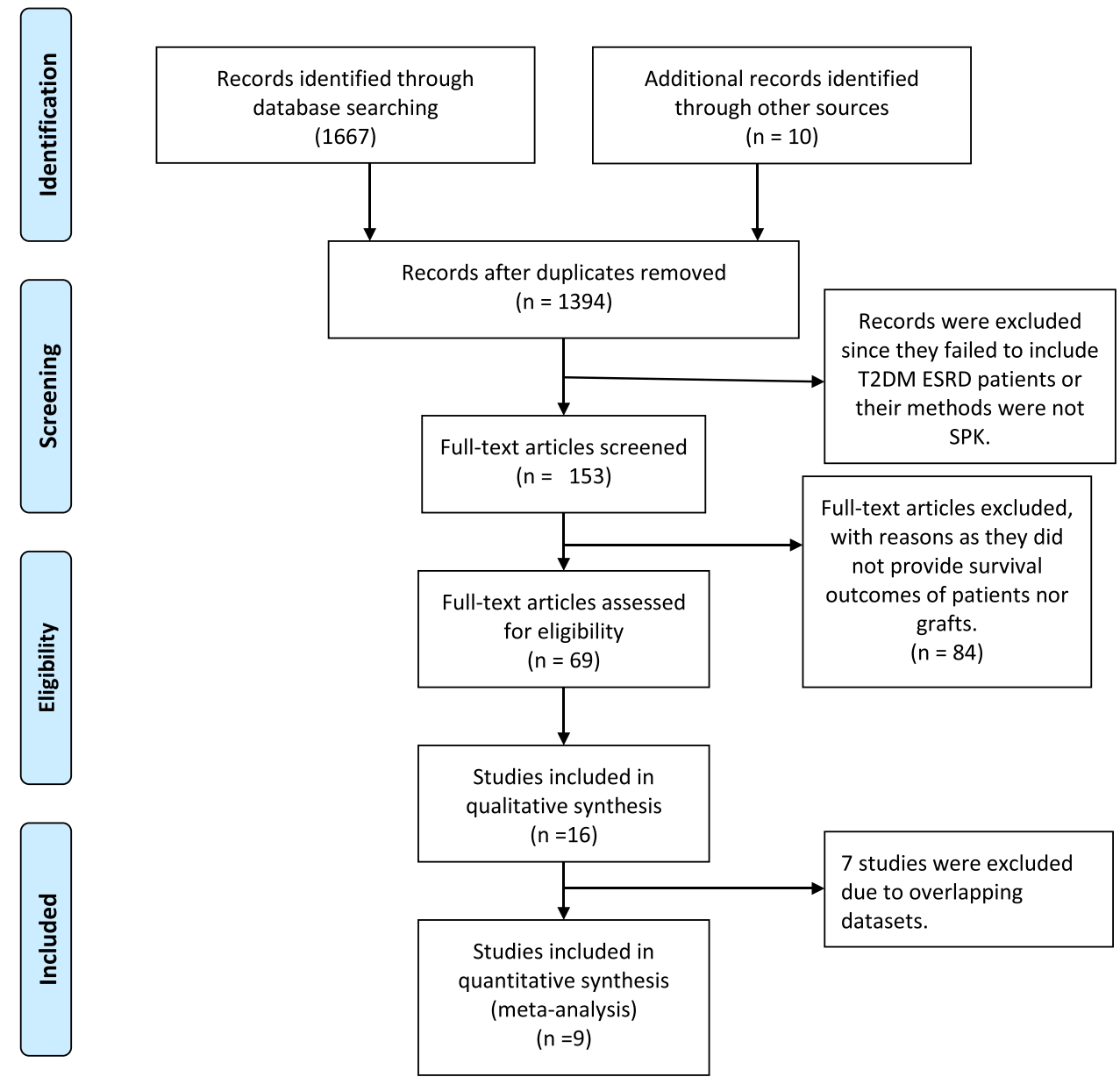

efficacy of SPK for T2DM remained controversial in 2016 [32]. Al-qaoud et al. concluded that the outcomes of strictly selected T2DM recipients mirrored those of T1DM in a literature review [33]. Hitherto, no high-quality evidence was available for T2DM patients with SPK, neither the precise survival risks of T2DM patients undertaking SPK compared with T1DM SPK patients or T2DM KTA patients. With several studies from different countries emerging between 2016 and 2020 [17, 18, 26-28], this study conducted a systematic review and meta-analysis to identify, collect, and synthesize all evidence reporting the survival outcomes of T2DM-ESKD recipients undertaking SPK worldwide, and make comparisons with their T1DM and KTA counterparts.

This systemic review included 9 studies comprising 811 T2DM-SPK recipients. The meta-5-year survival rates of patients and kidney grafts were above $90 \%$, and the meta-5-year survival rate of pancreas graft was $81 \%$.
The survival outcomes of T2DM were identical to those of T1DM. For comparison of survival outcomes between SPK and KTA, the patients' and grafts' survival rates in the SPK group were superior to those in the KTA group. Although studies from a different geographical area with different organ distribution systems, the $\mathrm{I}^{2} \mathrm{~s}$ were very low showing good homogeneity. The survival estimates of pancreas graft should be interpreted with caution given the various definitions reported in each program. Even though UNOS approved a standard definition in 2015 and the new policy was implemented in 2018 , these were not reflected in the included studies [34-36].

The synthesized survival comparisons between T1DM and T2DM verified that the overall survival outcomes of T2DM recipients were comparable with those of T1DM, despite that the baseline characteristics of T1DM and T2DM were notably different, with T2MD recipients of older age and higher BMI [21, 29, 31, 32]. The 


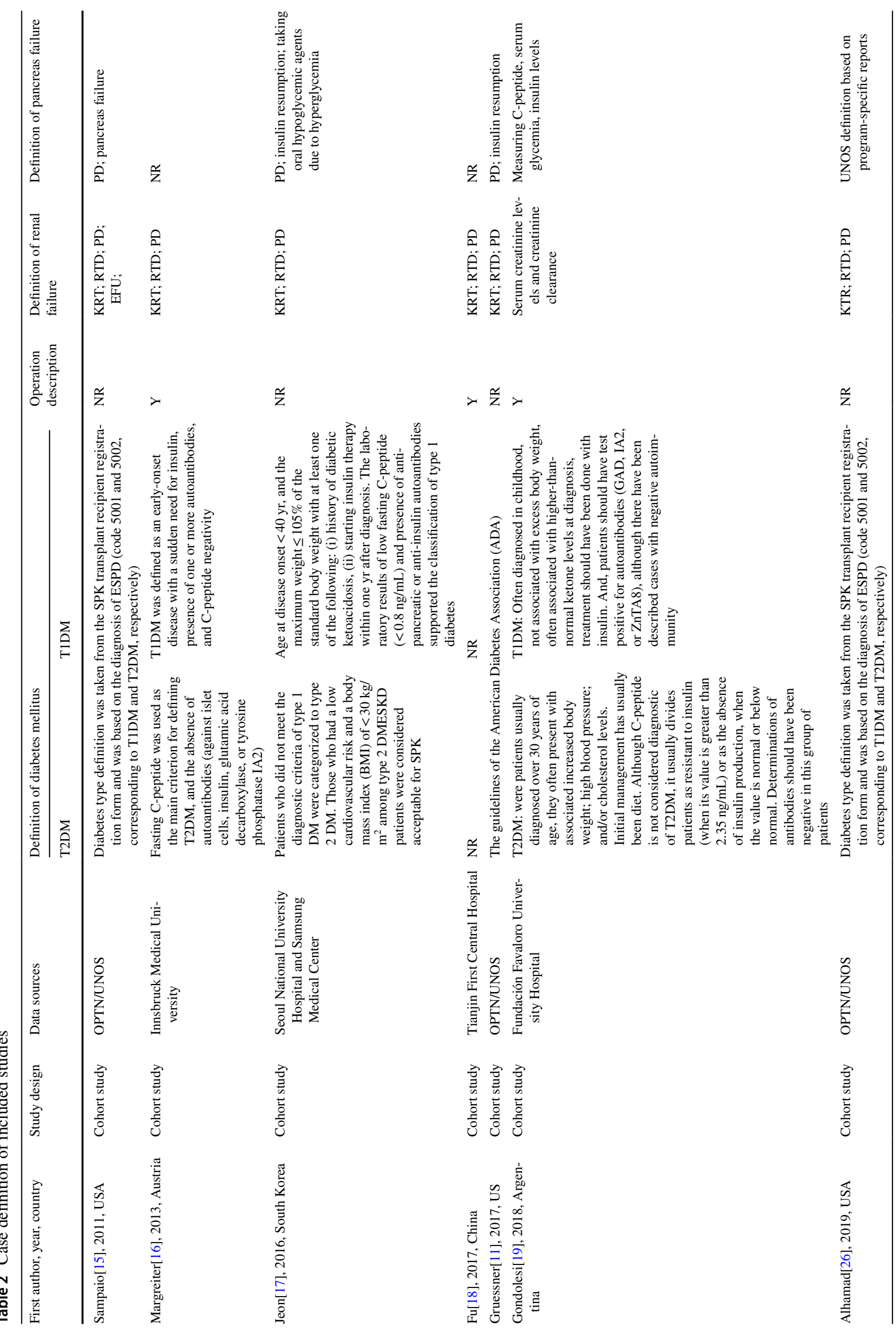




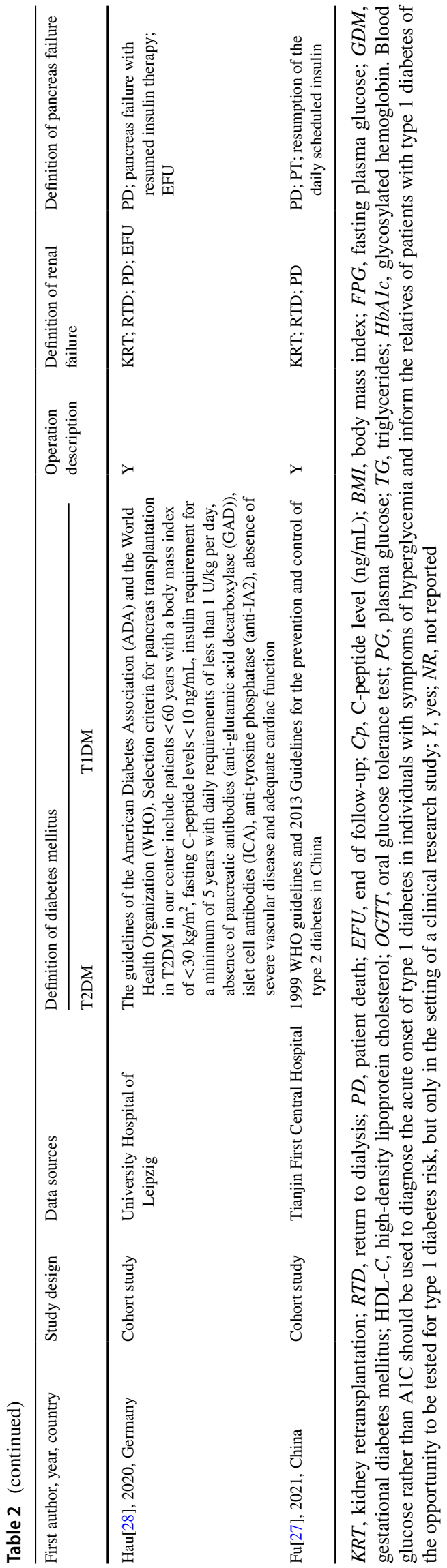

explanation was complicated by the ambiguous classification of T1DM and T2DM. Concerning the specific selection criteria, the consensus remains lacking but continuous efforts were made. In this review, there were center-specific criteria in selecting T2DM SPK recipients. Their criteria were based on the guidelines of the American Diabetes Association (ADA) and the World Health Organization (WHO) which were useful but had limited effect on selecting or decision-making process to help transplant surgeons to identify which kind of patients would benefit from SPK [37]. Jeon et al.'s study added lower cardiovascular risk and $\mathrm{BMI}<30 \mathrm{~kg} / \mathrm{m}^{2}$ [17]. Gondolesi et al. added C-peptide $>2.35 \mathrm{ng} / \mathrm{mL}$ [17]. Hau et al. considered T2DM patients with age $<60$ years, $\mathrm{BMI}<30 \mathrm{~kg} / \mathrm{m}^{2}$, and fasting C-p $<10 \mathrm{ng} / \mathrm{mL}$ [28]. Margreiter et al. [16] concluded that T2DM-ESKD patients with low coronary risk profile and age $\leq 55$ years may have a favorable outcome from SPK. Previously, several attempts had been made for this issue. Sener et al. [38] had proposed criteria for pancreas transplantation in T2DM in 2010, suggesting C-peptide level, BMI, and pre-operation cardiovascular disease be considered. Dean et al. [38] mentioned T2DM with low insulin requirements would probably benefit from pancreas transplantation. Previously, mostly mentioned factors were C-peptide level, BMI, onset of DM [21-23], and recipient's age [24]. While in 2018, UNOS amended the qualifying criteria and abandoned the maximal allowable BMI and C-peptide, and the policy was implemented in 2019 [33, 39]. Additionally, the novel subgroups of DM proposed in 2018 with a refined classification based on glutamate decarboxylase antibodies, age at diagnosis, BMI, HbA1c, and homeostatic model assessment 2 estimates of $\beta$-cell function and insulin resistance could also serve as a reference in making criteria [40].

For the comparison of SPK and KTA among T2DM patients, kidneys and patients' survival outcomes after SPK were more favorable than those after KTA. The metaHRs were dominated by Alhamad et al.'s study [26] with a weight of about $80 \%$. Alhamad et al.'s study [26] was a retrospective design based on the national database, with multiple factors adjusted in the survival analysis. However, some covariables like the duration of diabetes, insulin dose before transplantation, waiting time, and other factors reflecting diabetes-related comorbidities of recipients and donor factors which might be significantly different were not reported and adjusted. Therefore, the significant hazard ratio of KTA compared with SPK should be interpreted with caution. Prospective randomized studies which could control for confounders were still lacking.

Surgical, infectious, and immunological complications after SPK have been tricky issues for a long 
Table 3 Quality assessment: modified Newcastle-Ottawa scale for cohort studies (11 stars total)

\begin{tabular}{|c|c|c|c|c|c|c|c|c|c|}
\hline \multirow[t]{2}{*}{ Author, year } & \multicolumn{4}{|c|}{ Selection } & \multirow{2}{*}{$\begin{array}{l}\text { Comparability } \\
\text { C1 }\end{array}$} & \multicolumn{3}{|c|}{ Outcome } & \multirow[t]{2}{*}{ Total stars } \\
\hline & $\mathrm{S} 1$ & $\mathrm{~S} 2$ & S3 & $\mathrm{S} 4$ & & O1 & $\mathrm{O} 2$ & $\mathrm{O} 3$ & \\
\hline Sampaio[15], 2011 & $* *$ & $*$ & $*$ & & $*$ & $*$ & - & - & $6 / 11$ \\
\hline $\begin{array}{l}\text { Margreiter[16], } \\
2013\end{array}$ & & $*$ & $*$ & & - & $*$ & $* *$ & - & $5 / 11$ \\
\hline Jeon[17], 2016 & $* *$ & $*$ & $*$ & $*$ & - & $*$ & $*$ & - & $7 / 11$ \\
\hline $\mathrm{Fu}[18], 2017$ & $*$ & * & * & * & - & - & - & - & $4 / 11$ \\
\hline $\begin{array}{l}\text { Gruessner[11], } \\
2017\end{array}$ & $* *$ & NA & $*$ & $*$ & NA & $*$ & $*$ & - & $6 / 9$ \\
\hline $\begin{array}{l}\text { Gondolesi[19], } \\
2018\end{array}$ & & * & * & * & - & * & - & - & $4 / 11$ \\
\hline Alhamad[26], 2019 & ** & * & * & * & * & $*$ & * & - & $8 / 11$ \\
\hline $\mathrm{Hau[28],} 2020$ & & * & * & * & - & * & $* *$ & - & $6 / 11$ \\
\hline $\mathrm{Fu}[27], 2021$ & $*$ & * & * & * & $*$ & $*$ & - & $*$ & $7 / 11$ \\
\hline
\end{tabular}

More stars (*) indicate higher quality of the study. S1, representativeness of exposed cohort; S2, selection of nonexposed cohort; S3, ascertainment of exposure; S4, study was published within 5 years (after 2016); $\mathrm{C} 1$, comparability of the cohort on basis of design or analysis; O1, assessment of outcome; O2, was followup long enough for outcomes to occur ; O3, adequacy of follow-up; $N A$, not applicable; For details, please refer to SDC-Table S2. period [41-45]. The present analysis indicated that the T2DM group had a higher risk of renal graft DGF. DGF of kidney graft was reported to be significantly associated with weight [15]. Most T2DM recipients were overweight or obese compared with T1DM patients, which could cause a higher DGF risk. The rejection rate, infection rate, and DGF rate of pancreas graft were not significantly inferior. The estimates were limited by the insufficient description of definitions of each complication and definition of pancreas graft failure, further hindering the comparison between groups. As pointed out by Dean et al. [6], currently, a lack of uniform definition regarding complications limited the broader application of collected data. The integrated results about complication risk ratio should be interpreted with caution.

\section{Strengths and limitations}

This study has several strengths. The major one is that it is the first attempt to integrate the survival rate of patients and grafts of T2DM after SPK with software (Engauge Digitize) and HR calculation spreadsheet (by Tierney et al. [21]) with rigorous methodology. In addition, the studies included in this meta-analysis were drawn from a variety of countries that increased its applicability across many populations and organ transplantation centers. Next, there was slight between-study heterogeneity, indicating that estimates of mortality varied significantly beyond chance. There were some limitations, and the major one was that the absence of clear definitions of complications and pancreas graft failure hindered the interpretation of meta-results. Additionally, a small number of studies were enrolled in the meta-analysis of complications risk, and the meta-estimate should be interpreted with caution. Another main pitfall was that some included studies failed to provide multivariable-adjusted data, which might increase the risk of Type 2 error [46]. Besides, though capturing survival data from figures in articles made a quantitative synthesize of time-to-event data possible and had been used widely [47-49], still it would have a slight degree of error. Therefore, transparency of original studies is advocated.

\section{Conclusions}

The synthesized survival estimates of T2DM-ESKD patients after SPK were above $90 \%$. Specifically, survival outcomes of T2DM patients are comparable with that of T1DM, and for T2DM, SPK is superior to KTA. However, a uniform criterion of T2DM subsets that would benefit the most from SPK and clearly defined diagnosis standards of SPK-related complications are urgent to be made.

\section{Availability of data and code}

The datasets or code used or analyzed during the current study are available from the corresponding author on reasonable request. 
Fig. 2 A Forest plot of metaanalysis of 1-year, 3-year, and 5-year patient survival rate after SPK. B Forest plot of metaanalysis of 1-year, 3-year, and 5 -year kidney graft survival rates after SPK. C Forest plot of meta-analysis of 1-year, 3-year, and 5-year pancreas graft survival rates after SPK

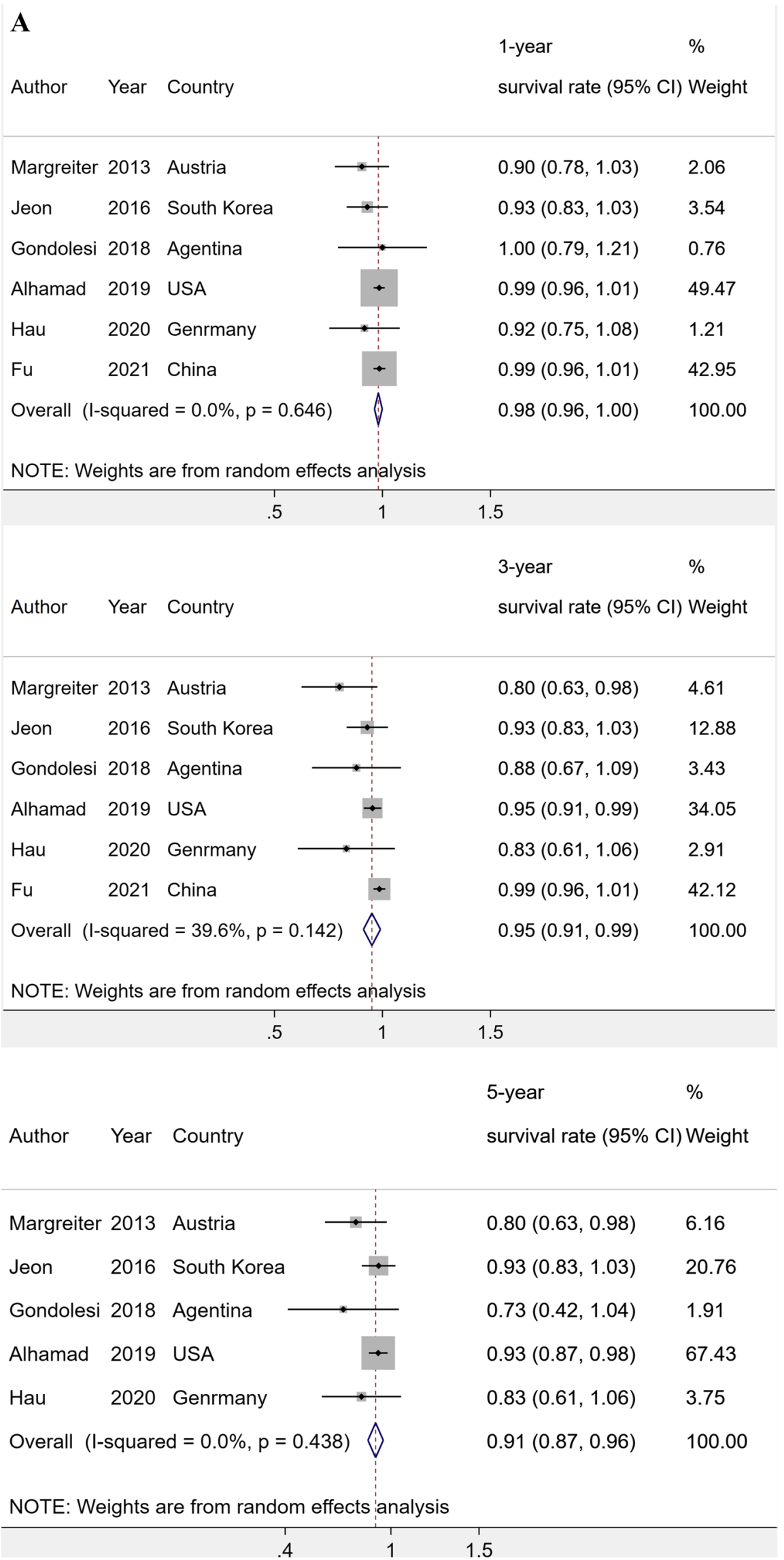


Fig. 2 (continued)

B

\begin{tabular}{|c|c|c|c|c|}
\hline \multicolumn{3}{|l|}{$\mathbf{D}$} & \multicolumn{2}{|l|}{ 1-year } \\
\hline Author & Year & Country & survival rate $(95 \%$ & Weight \\
\hline Margreiter & 2013 & $\longrightarrow$ & $0.86(0.71,1.01)$ & 2.04 \\
\hline Jeon & 2016 & South Korea & $0.93(0.83,1.03)$ & 5.01 \\
\hline Gondolesi & 2018 & Argentina & $1.00(0.79,1.21)$ & 1.08 \\
\hline Alhamad & 2019 & USA & $0.97(0.95,1.00)$ & 71.56 \\
\hline Hau & 2020 & Germany & $0.92(0.75,1.08)$ & 1.71 \\
\hline $\mathrm{Fu}$ & 2021 & China & $0.95(0.91,1.00)$ & 18.60 \\
\hline Overall $(\mathrm{I}-$ & -square & $d=0.0 \%, p=0.611)$ & $0.97(0.94,0.99)$ & 100.00 \\
\hline
\end{tabular}

$\begin{array}{lll}.5 & 1 & 1.5\end{array}$

Author Year Country

3-year

$\%$

survival rate $(95 \% \mathrm{Cl})$ Weight

Margreiter 2013 Austria

Jeon 2016 South Korea

Gondolesi 2018 Argentina

Alhamad 2019 USA

Hau 2020 Germany

Fu 2021 China

$0.80(0.63,0.98)$

2.71

$0.93(0.83,1.03)$

8.96

$0.88(0.67,1.09)$

1.93

$0.94(0.90,0.98)$

51.51

$0.83(0.61,1.06)$

1.62

$0.95(0.91,1.00)$

33.27

Overall (I-squared $=0.0 \%, p=0.556)$

i.

$0.94(0.91,0.97)$

100.00

NOTE: Weights are from random effects analysis

.5

1

1.5

5-year

$\%$

Author Year Country

survival rate $(95 \% \mathrm{CI})$ Weight

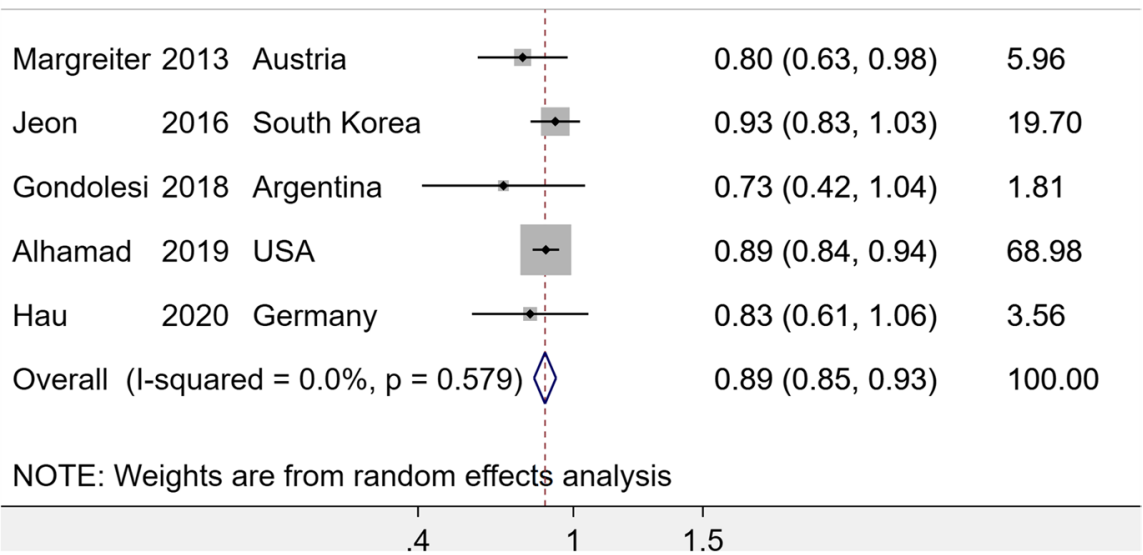


Fig. 2 (continued)

C

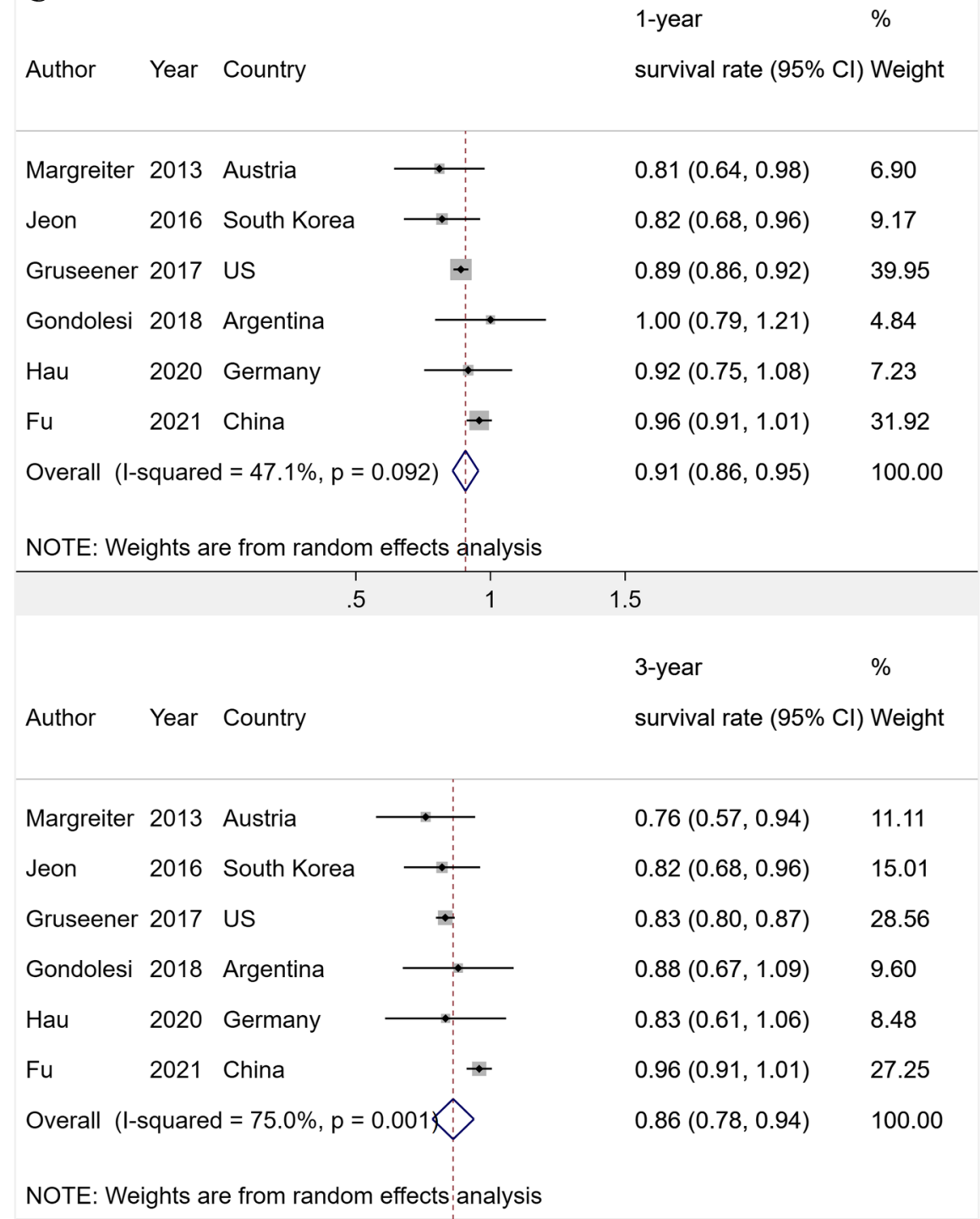

Author Year Country survival rate $(95 \% \mathrm{Cl})$ Weight

\begin{tabular}{|c|c|c|c|c|}
\hline Margreiter & 2013 & Austria & $0.76(0.57,0.94)$ & 3.15 \\
\hline Jeon & 2016 & South Korea & $0.82(0.68,0.96)$ & 5.33 \\
\hline Gruseener & 2017 & US & $0.81(0.78,0.84)$ & 88.33 \\
\hline Gondolesi & 2018 & Argentina & $0.73(0.42,1.04)$ & 1.08 \\
\hline $\mathrm{Hau}$ & 2020 & Germany & $0.83(0.61,1.06)$ & 2.11 \\
\hline Overall (I-s & squarec & $d=0.0 \%, p=0.964)$ & $0.81(0.78,0.84)$ & 100.00 \\
\hline
\end{tabular}


Fig. 3 A Forest plot for metaanalysis of patient hazard ratios of T2DM compared with T1DM in SPK transplant recipients.

B Forest plot for meta-analysis of kidney graft hazard ratios of T2DM compared with T1DM in SPK transplant recipients. C Forest plot for meta-analysis of pancreas hazard ratios of T2DM compared with T1DM in SPK transplant recipients
A

$\begin{array}{llll}\text { Name Year country } & \text { HR }(95 \% \mathrm{Cl}) & \text { Weight }\end{array}$

B

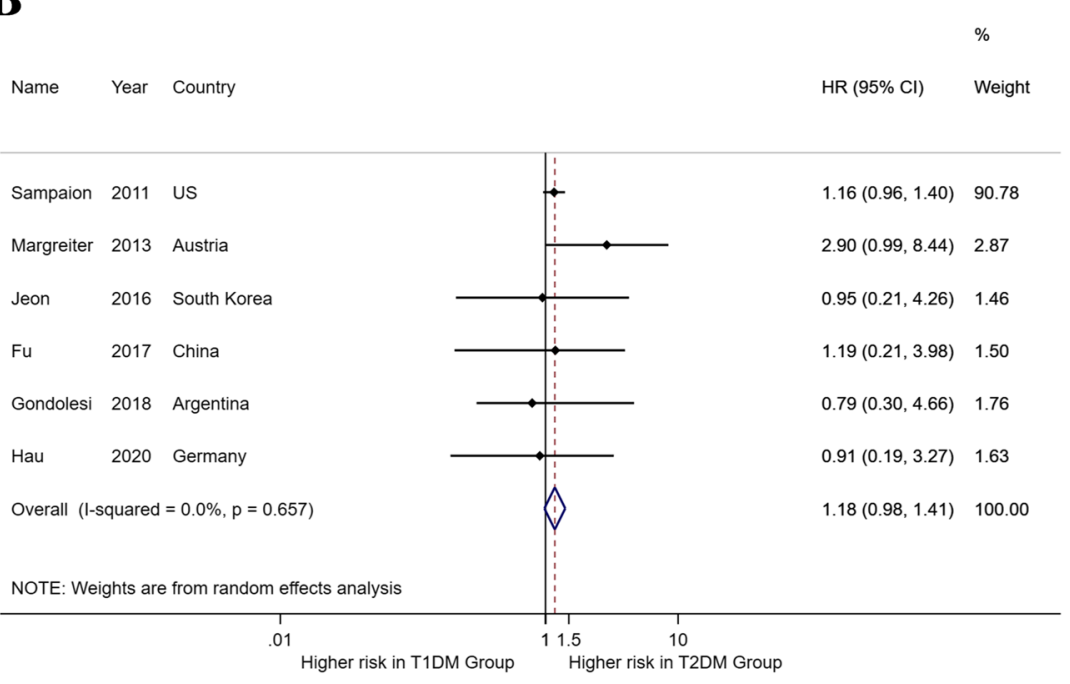

C

$\%$

$\mathrm{HR}(95 \% \mathrm{Cl}) \quad$ Weight

Sampaion 2011 US

Margreiter 2013 Austria

2016 South Korea

Fu 2017 China

Gondolesi 2018 Argentina

Hau

Overall (I-squared $=0.0 \%, p=0.632$ )

NOTE: Weights are from random effects analysis
$1.08(0.91,1.28) \quad 91.66$

$2.50(1.01,6.22) \quad 3.21$

$0.95(0.21,4.26) \quad 1.18$

$1.19(0.30,4.68) \quad 1.42$

$0.94(0.21,4.27) \quad 1.16$

$0.81(0.20,3.29) \quad 1.36$

$1.10(0.94,1.30) \quad 100.00$ 
Fig. 4 A Forest plot of metaanalysis of patient hazard ratios of SPK compared with KTA in T2DM transplant recipients. B Forest plot of meta-analysis of kidney hazard ratios of SPK compared with KTA in T2DM transplant recipients
A

$\%$

Name Year Country HR $(95 \% \mathrm{Cl}) \quad$ Weight

\begin{tabular}{|c|c|c|c|c|c|}
\hline Margreiter & 2013 & Austria & $i$ & $1.44(0.47,4.34)$ & 10.07 \\
\hline Alhamad & 2018 & US & & $2.56(1.72,3.84)$ & 76.47 \\
\hline Hau & 2020 & Germany & $i$ & $1.62(0.42,6.26)$ & 6.73 \\
\hline $\mathrm{Fu}$ & 2021 & China & & $2.43(0.42,6.26)$ & 6.73 \\
\hline \multicolumn{3}{|c|}{ Overall $(1-$ squared $=0.0 \%, p=0.746)$} & & $2.33(1.64,3.32)$ & 100.00 \\
\hline \multicolumn{6}{|c|}{ NOTE: Weights are from random effects analysis } \\
\hline
\end{tabular}

B $\%$

Name Year Country HR $(95 \% \mathrm{Cl}) \quad$ Weight

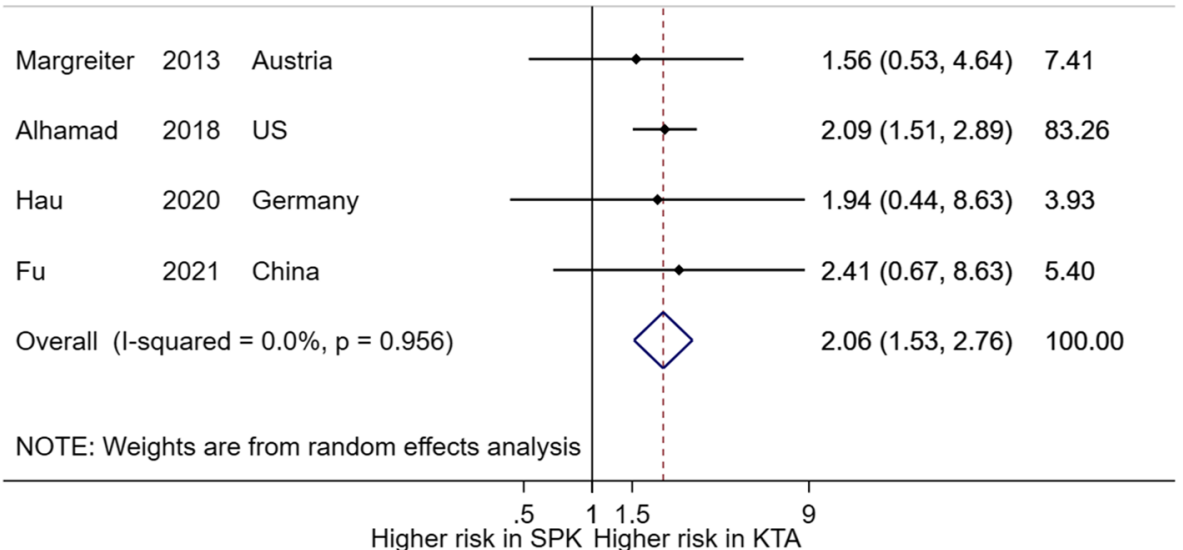




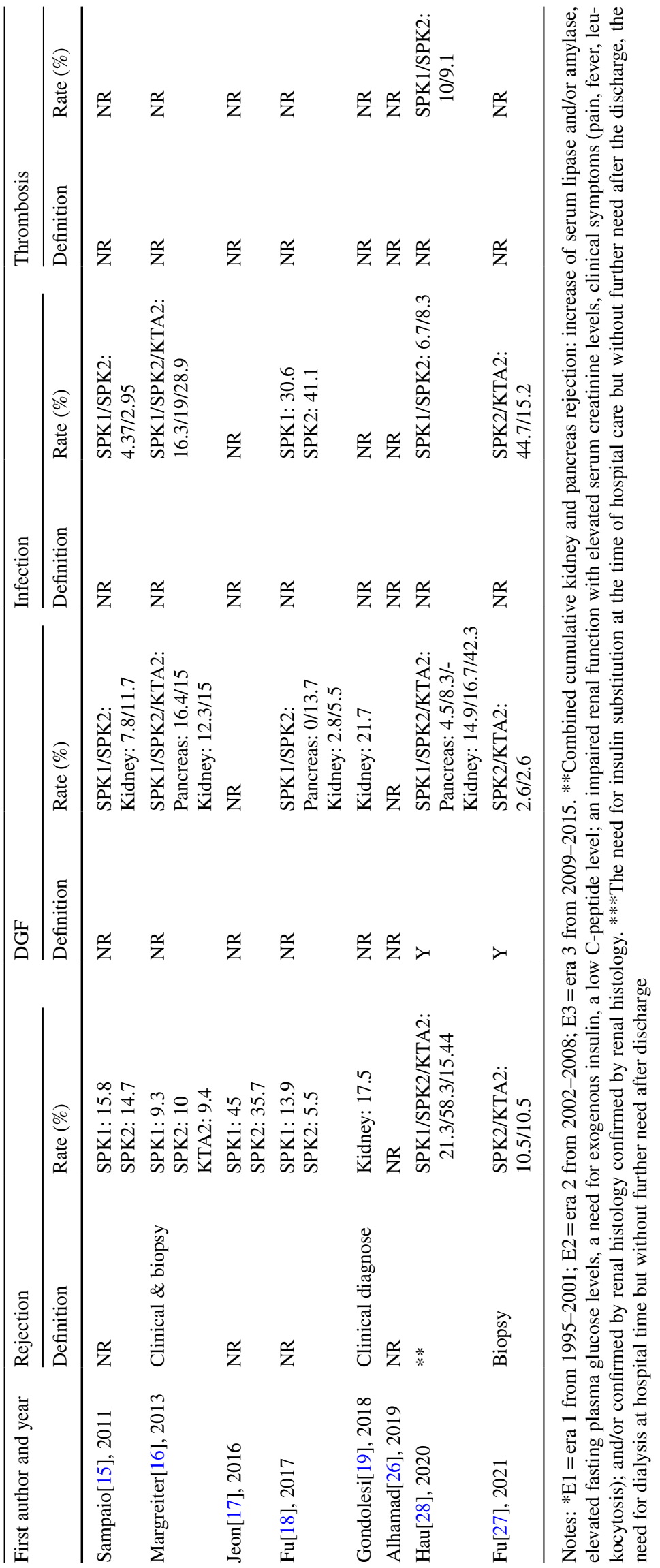


Supplementary Information The online version contains supplementary material available at https://doi.org/10.1007/s00423-021-02249-y.

Authors' contributions Yingxin Fu designed the study; Yu Cao, Xiaoli Liu, and Kaiwen Ni performed the research. Yu Cao did the data analysis. Yu Cao and Xiaoli Liu interpreted data and drafted the manuscript. Xiangyu Lan helped to collect the data and LL helped to revise the manuscript. Yingxin Fu arbitrated the differences and revised the manuscript.

Funding National Natural Science Foundation of China (NSFC) (NO. 8197033298); Tianjin Health Science and Technology Program (NO. ZC20167, NO. RC20090, NO.RC20128, NO.ZC20122, NO.RC20111, NO.ZC20227). The funders of the study had no role in study design, data collection, data analysis, data interpretation, or writing of the manuscript.

\section{Declarations}

Ethics approval Not applicable.

Conflict of interest The authors declare no competing interests.

Open Access This article is licensed under a Creative Commons Attribution 4.0 International License, which permits use, sharing, adaptation, distribution and reproduction in any medium or format, as long as you give appropriate credit to the original author(s) and the source, provide a link to the Creative Commons licence, and indicate if changes were made. The images or other third party material in this article are included in the article's Creative Commons licence, unless indicated otherwise in a credit line to the material. If material is not included in the article's Creative Commons licence and your intended use is not permitted by statutory regulation or exceeds the permitted use, you will need to obtain permission directly from the copyright holder. To view a copy of this licence, visit http://creativecommons.org/licenses/by/4.0/.

\section{References}

1. USCDC, National Diabetes Statistics Report, 2020. Atlanta, GA: Centers for Disease Control and Prevention, U.S. Dept of Health and Human Services, 2020

2. Saeedi P, Petersohn I, Salpea P et al (2019) Global and regional diabetes prevalence estimates for 2019 and projections for 2030 and 2045: results from the International Diabetes Federation Diabetes Atlas, 9(th) edition. Diabetes Res Clin Pract 157:107843. https://doi.org/10.1016/j.diabres.2019.107843

3. Hu C, Jia W (2018) Diabetes in China: epidemiology and genetic risk factors and their clinical utility in personalized medication. Diabetes 67:3-11. https://doi.org/10.2337/dbi17-0013

4. Saran R, Robinson B, Abbott KC et al (2020) US Renal Data System 2019 Annual Data Report: Epidemiology of Kidney Disease in the United States. Am J Kidney Dis 75:A6-07. https://doi.org/ 10.1053/j.ajkd.2019.09.003

5. Kelly WD, Lillehei RC, Merkel FK, Idezuki Y, Goetz FC (1967) Allotransplantation of the pancreas and duodenum along with the kidney in diabetic nephropathy. Surgery 61:827-837

6. Dean PG, Kukla A, Stegall MD, Kudva YC (2017) Pancreas transplantation. BMJ 357:j1321. https://doi.org/10.1136/bmj.j1321
7. Orlando G, Stratta RJ, Light J (2011) Pancreas transplantation for type 2 diabetes mellitus. Curr Opin Organ Transplant 16:110-115. https://doi.org/10.1097/MOT.0b013e3283424d1f

8. Chadban SJ, Ahn C, Axelrod DA et al (2020) KDIGO clinical practice guideline on the evaluation and management of candidates for kidney transplantation. Transplantation 104:S11-103. https://doi.org/10.1097/TP.0000000000003136

9. Gruessner AC, Sutherland DE (2008) Pancreas transplant outcomes for United States (US) cases as reported to the United Network for Organ Sharing (UNOS) and the International Pancreas Transplant Registry (IPTR). Clin Transpl. 4556

10. Gruessner AC, Sutherland DE, Gruessner RW (2010) Pancreas transplantation in the United States: a review. Curr Opin Organ Transplant 15:93-101. https://doi.org/10.1097/MOT.0b013e3283 $3552 \mathrm{~d} 2$

11. Gruessner AC, Laftavi MR, Pankewycz O, Gruessner RWG (2017) Simultaneous pancreas and kidney transplantation-is it a treatment option for patients with type 2 diabetes mellitus? An analysis of the International Pancreas Transplant Registry. Current Diabetes Reports;17. https://doi.org/10.1007/s11892-017-0864-5

12. The Eurotransplant Community. 2019. Eurotransplant Annual Report 2019. https://www.eurotransplant.org/wp-content/uploa ds/2020/06/Annual-Report-2019.pdf.

13. Moher D, Liberati A, Tetzlaff J, Altman DG (2009) Preferred reporting items for systematic reviews and meta-analyses: the PRISMA statement. J Clin Epidemiol 62:1006-1012. https://doi. org/10.1016/j.jclinepi.2009.06.005

14. Huang J, Millis JM, Mao Y et al (2012) A pilot programme of organ donation after cardiac death in China. Lancet 379:862-865. https://doi.org/10.1016/S0140-6736(11)61086-6

15. Sampaio MS, Kuo HT, Bunnapradist S (2011) Outcomes of simultaneous pancreas-kidney transplantation in type 2 diabetic recipients. Clin J Am Soc Nephrol 6:1198-1206. https://doi.org/ 10.2215/CJN.06860810

16. Margreiter C, Resch T, Oberhuber R et al (2013) Combined pancreas-kidney transplantation for patients with end-stage nephropathy caused by type- 2 diabetes mellitus. Transplantation 95:1030-1036. https://doi.org/10.1097/TP.0b013e3182861945

17. Jeon HJ, Koo TY, Han M et al (2016) Outcomes of dialysis and the transplantation options for patients with diabetic end-stage renal disease in Korea. Clin Transplant 30:534-544. https://doi.org/10. 1111/ctr.12719

18. Fu YX, Song WL, Mo C, Feng G (2017) Simultaneous pancreaskidney transplantations for type 2 diabetes mellitus with end stage renal diesase- 73 cases report. Chinese Journal of Organ Transplantation 38:1-05. https://doi.org/10.3760/cma.j.issn.0254-1785. 2017.01.001

19. Gondolesi GE, Aguirre NF, Ramisch DA et al (2018) Pancreas transplantation at a single Latin-American Center; overall results with type 1 and type 2 diabetes mellitus. Transplant Proc 50:1475-1481. https:// doi.org/10.1016/j.transproceed.2018.03.022

20. Metelli S, Chaimani A (2020) Challenges in meta-analyses with observational studies. Evidence Based Mental Health 23:83. https://doi.org/10.1136/ebmental-2019-300129

21. Tierney JF, Stewart LA, Ghersi D, Burdett S, Sydes MR (2007) Practical methods for incorporating summary time-to-event data into meta-analysis. Trials 8:16. https://doi.org/10.1186/ $1745-6215-8-16$

22. Higgins JP, Altman DG, Gotzsche PC et al (2011) The Cochrane Collaboration's tool for assessing risk of bias in randomised trials. BMJ 343:d5928. https://doi.org/10.1136/bmj.d5928

23. Wells G, Shea B, O'Connell D, et al. The Newcastle-Ottawa Scale (NOS) for assessing the quality of nonrandomised studies in meta-analyses. Department of Epidemiology and Commuunity 
Medicine, University of Ottawa. 2013. http://www.ohri.ca/progr ams/clinical_epidemiology/oxford.asp. (Accessed on 12 Dec 2018).

24. Mao C, Fu XH, Yuan JQ, et al. Tong-xin-luo capsule for patients with coronary heart disease after percutaneous coronary intervention. Cochrane Database Syst Rev 2015:D10237. https://doi.org/ 10.1002/14651858.CD010237.pub2

25. Sedgwick P, Marston L (2015) How to read a funnel plot in a meta-analysis. BMJ 351:h4718. https://doi.org/10.1136/bmj. h4718

26. Alhamad T, Kunjal R, Wellen J et al (2020) Three-month pancreas graft function significantly influences survival following simultaneous pancreas-kidney transplantation in type 2 diabetes patients. Am J Transplant 20:788-796. https://doi.org/10.1111/ajt.15615

27. Fu Y, Cao Y, Wang H et al (2021) Metabolic outcomes and renal function after simultaneous kidney/pancreas transplantation compared with kidney transplantation alone for type 2 diabetes mellitus patients. Transpl Int. https://doi.org/10.1111/tri.13892

28. Hau HM, Jahn N, Brunotte M et al (2020) Short and long-term metabolic outcomes in patients with type 1 and type 2 diabetes receiving a simultaneous pancreas kidney allograft. BMC Endocr Disord 20:30. https://doi.org/10.1186/s12902-020-0506-9

29. Andacoglu OM, Himmler A, Geng X et al (2019) Comparison of glycemic control after pancreas transplantation for Type 1 and Type 2 diabetic recipients at a high volume center. Clin Transplant 33:e13656. https://doi.org/10.1111/ctr.13656

30. Light J, Tucker M (2013) Simultaneous pancreas kidney transplants in diabetic patients with end-stage renal disease: the 20-yr experience. Clin Transplant 27:E256-E263. https://doi.org/10. 1111/ctr. 12100

31. Singh RP, Rogers J, Farney AC et al (2008) Do pretransplant C-peptide levels influence outcomes in simultaneous KidneyPancreas Transplantation? Transpl Proc 40:510-512. https://doi. org/10.1016/j.transproceed.2008.01.048

32. Kandaswamy R, Stock PG, Gustafson SK et al (2019) OPTN/ SRTR 2017 Annual Data Report: Pancreas. Am J Transplant 19(Suppl 2):124-183. https://doi.org/10.1111/ajt.15275

33. Kandaswamy R, Stock PG, Gustafson SK et al (2018) OPTN/ SRTR 2016 Annual Data Report: Pancreas. Am J Transplant 18:114-171. https://doi.org/10.1111/ajt.14558

34. Kandaswamy R, Stock PG, Gustafson SK et al (2017) OPTN/ SRTR 2015 Annual Data Report: Pancreas. Am J Transplant 17:117-173. https://doi.org/10.1111/ajt.14125

35. Chan CM, Chim TM, Leung KC et al (2016) Simultaneous pancreas and kidney transplantation as the standard surgical treatment for diabetes mellitus patients with end-stage renal disease. Hong Kong Med J 22:62-69. https://doi.org/10.12809/hkmj154613

36. Al-Qaoud TM, Odorico JS, Redfield RR (2018) Pancreas transplantation in type 2 diabetes: expanding the criteria. Curr Opin Organ Transplant 23:454-460. https://doi.org/10.1097/MOT. 0000000000000553
37. Ciancio G, Burke GW (2014) Type 2 diabetes: is pancreas transplantation an option? Curr Diab Rep 14:542. https://doi.org/10. 1007/s11892-014-0542-9

38. Sener A, Cooper M, Bartlett ST (2010) Is there a role for pancreas transplantation in type 2 diabetes mellitus? Transplantation 90:121-123. https://doi.org/10.1097/TP.0b013e3181e5b7e6

39. UNOS News. https://unos.org/news/removing-bmi-and-cpept ide-from-kidney-pancreas-waiting-time-criteria 2019; [accessed 1 March 2021].

40. Ahlqvist E, Storm P, Karajamaki A et al (2018) Novel subgroups of adult-onset diabetes and their association with outcomes: a datadriven cluster analysis of six variables. Lancet Diabetes Endocrinol 6:361-369. https://doi.org/10.1016/S2213-8587(18)30051-2

41. Banga N, Hadjianastassiou VG, Mamode N et al (2012) Outcome of surgical complications following simultaneous pancreas-kidney transplantation. Nephrol Dial Transplant 27:1658-1663. https:// doi.org/10.1093/ndt/gfr502

42. Michalak G, Kwiatkowski A, Bieniasz M et al (2005) Infectious complications after simultaneous pancreas-kidney transplantation. Transpl Proc 37:3560-3563. https://doi.org/10.1016/j.trans proceed.2005.09.078

43. Shahrestani S, Tran HM, Pleass HC, Hawthorne WJ (2018) Optimal surgical management in kidney and pancreas transplantation to minimise wound complications: a systematic review and metaanalysis. Annals of Medicine and Surgery 33:24-31. https://doi. org/10.1016/j.amsu.2018.08.006

44. Soo Lee J, Sik Kim K, Woo Cho C, et al. Outcomes following simultaneous pancreas-kidney transplantation: single center experience in Korea. Trends in Transplantation 2017;10. https://doi. org/10.15761/TiT.1000235

45. Steurer W, Malaise J, Mark W, Koenigsrainer A, Margreiter R (2005) Spectrum of surgical complications after simultaneous pancreas-kidney transplantation in a prospectively randomized study of two immunosuppressive protocols. Nephrol Dial Transplant 20:i54-61. https://doi.org/10.1093/ndt/gfh1083

46. Hill CJ, Courtney AE, Cardwell CR et al (2015) Recipient obesity and outcomes after kidney transplantation: a systematic review and meta-analysis. Nephrol Dial Transplant 30:1403-1411. https://doi.org/10.1093/ndt/gfv214

47. Burda BU, O'Connor EA, Webber EM, Redmond N, Perdue LA (2017) Estimating data from figures with a web-based program: considerations for a systematic review. Research Synthesis Methods 8:258-262. https://doi.org/10.1002/jrsm.1232

48. Gao Y, Zhang K, Xi H, et al. Diagnostic and prognostic value of circulating tumor DNA in gastric cancer: a meta-analysis. Oncotarget 2017;8:6330-40. https://doi.org/10.18632/oncotarget.14064

49. Valter Silva APVD. Can data extraction from figures perform a meta-analysis.

Publisher's Note Springer Nature remains neutral with regard to jurisdictional claims in published maps and institutional affiliations. 